\title{
OPACIDADE E VISIBILIDADE DA PATERNIDADE NA REPRODUÇÃO ADOLESCENTE
}

\author{
OPACITY AND VISIBILITY OF PATERNITY \\ IN ADOLESCENT REPRODUCTION
}

Alberto Olavo Advíncula Reis ${ }^{1}$

REIS, A. O. A. Opacidade e Visibilidade da Paternidade na Reprodução Adolescente. Rev. Bras. Cresc. Desenv. Hum., São Paulo, 7(2), 1997.

Resumo: O presente trabalho visa, através da análise de textos de divulgação científica, identificar as condições epistemológicos que propiciaram a emergência da questão da paternidade adolescente no âmbito das preocupações da Saúde Pública referentes à gravidez e à maternidade juvenis. Além disto, a investigação em pauta enseja promover uma reflexão destinada a elucidar o papel desempenhado pela ocultação do tema da paternidade nos textos científicos que têm, como objeto, o processo reprodutivo da mulher adolescente.

Palavras-chave: paternidade adolescente, adolescente grávida, saúde pública.

\section{INTRODUÇÃO}

O presente trabalho insere-se na continuidade de uma série de investigações referentes às temáticas contempladas pelo discurso da Saúde Pública, visando à adolescente grávida (REIS,1992;1993;1994;1998). Ele se propoe evidenciar a base epistemológica que possibilitou a emergência da questão do género no ambito da problemática da gravidez e maternidade da adolescente e estabelecer a importancia dos efeitos da ocultação do papel da paternidade na equação desta maternidade.

O princípio metodológico adorado nessas pesquisas tem, como pressuposto, a idéia de que, sob a dimensão manifesta da literatura científica constituída pelos termos dos textos destinados à comunicação intencional, existe uma dimensão latente. Esta última compõe-se como um nível implícito, formado porintenções e ideias que permanecem à sombra das motivações explícitas dos textos. Este nível mais velado não é, contudo, desprovido de eficácia, uma vez que produz, sistematicamente, significações no corpo manifesto do discurso, e nem sequer subtrai-se à apreensão e à compreensão. Nos termos de Bardin, dir-se-ia que o "não aparente - o oculto retido por qualquer mensagem - seria passível de análise possibilitando a emergência do potencial do inédito" (BARDIN, 1980, p.9). São operações analíticas específicas que permitem tal emergência.

Na presente pesquisa adotaram-se, para tanto, os procedimentos de análise de conteúdo direcionada na perspectiva apontadapor SOARES (1969). Assim, evidenciaram-se, em primeiro lugar, as áreas de conhecimento às quais se agregavam os textos de Saúde Pública referentes à adolescente grávida.

Em seguida, procedeu-se à contextualização da realidade sócio-histórica no interior da qual se realizavam as ligações do discurso da Saúde com as diferentes áreas do conhecimento. Além

1 Professor Doutor do Departamento de Saúde Materno-infantil da Faculdade de Saúde Pública da Universidade de São Paulo. End Av. Dr. Arnaldo, 715, 2 Andar Depto. Saúde Materno-Infantil. São Paulo-SP Cep: 01246-904 Tel: (011) 3066-7702. 
destes passos, estabeleceram-se, através de uma análise de conteúdo temática, os principais temas veiculados pelos textos científicos no período considerado pelo estudo.

Deste modo, as áreas de conhecimento às quais os textos se remetem, quando devidamente contextualizadas, permitem que se façam emergir as tensões oriundas de paradigmas concorrentes em vista de um poder hegemônico. O quadro sucessivo destes paradigrnas dominantes, no sentido em que KUHN (1978) os define, enseja, por sua vez, a possibilidade de construção de um perfil epistemológico da Saúde Pública. Tal perfil permitiria tanto situar o momento epistemológico de emergência da questão da paternidade, bem como o sentido de sua ocultação no âmbito da problemática da maternidade adolescente.

\section{CONCEITUAÇÃO}

A Organização Mundial da Saúde (OMS, 1975) define a adolescência como um período em que se operam transformações bio-fisiológicas no tocante ao amadurecimento sexual, evoluções identificatórias de natureza psicológica e desenvolvimento de um processo de emancipação social e material do indivíduo. Muito embora a conceituação em pauta não implique limites rígidos, a OMS sugere que se considere adolescente todo indivíduo entre 10 e 14 anos e entre 15 e 19 anos. Tal critério, adotado amiúde nas pesquisas e estatísticas referentes à adolescência, corresponde, essencialmente, a um esforço de estabelecimento de parâmetros comuns capazes de permitir comparações pertinentes entre dados relativos à adolescência.

Em conformidade, então, com a conceituação e o critério da OMS, considera-se que a paternidade adolescente corresponde ao fato de um indivíduo tornar-se pai antes de completar 20 anos de idade. A paternidade adolescente, assim estabelecida, define-se na independência etária da parceira envolvida na reprodução sexual. Dá-se por evidente que o aspecto excessivamente construído desta definição deixa de lado considerações à respeito do relativismo social, cultural, étnico e psicológico da idéia geral de paternidade.

A importância de se contemplar a paternidade no processo reprodutivo da adolescência estriba-se em considerações bastante relevantes. Destaca-se, dentre elas, o fato de que se é verdade que a mãe adolescente nem sempre tem por parceiro um adolescente, não é raro, contudo, que a parceira de um pai adolescente seja, quase sempre uma adolescente.

Desta feita, considerar o processo reprodutivo do jovem, do ponto de vista da paternidade adolescente, permite que se aborde, de manei- ra mais integral, a questão da gravidez e da maternidade no âmbito da adolescência. Entretanto, tal perspectiva tornou-se possível somente a partir da década de 80. Retraçar e revelar os aspectos envolvidos nesta possibilidade constitui o objetivo deste trabalho.

\section{ATRANSFORMAÇÃO DOS PARADIGMAS}

Em uma investigação voltada para o le vantamento e análise dos textos de Saúde Pública registrados no Index Medicus referente à adolescência, gravidez e maternidade ao longo do período de 1930 a 1990, REIS (1993) pôde identificar que apenas a partir de 1980 é que começaram despontar temas relativos à paternidade. A figura do pai na equação da adolescente grávida havia, até então, sido de tal modo ocluída na literatura científica da área da Saúde que parecia que a maternidade, neste âmbito, fosse obra exclusiva da mulher.

Foi a alteração dos paradigmas discursivos atinentes à adolescente, advinda dos anos 60, que criou condições e articulou espaços para que a paternidade viesse, subseqüentemente, a ser contemplada no rol das preocupações da Saúde. Esta alteração remete-se ao falo de que, a partir de 1960, passou-se a assistir ao declínio, no âmbito da Saúde Pública, da temática bio-naturalista, que, até então, orientava os estudos e investigações sobre a adolescente.

A comparação dos textos da literatura internacional acerca dos temas “adolescência e gravidez” registrados, no Index Medicus, respectivamente nas décadas de 50 e 60 permite mostrar que houve uma mudança sensível nas áreas de conhecimento que serviam, então, de referência epistemológica para a construção do discurso da saúde pública, conforme indicado nas tabelas 1 e 2 .

A tabela 1 mostra os dados obtidos através da análise de conteúdo dirigida ao evidenciamento do referencial teórico norteador dos textos de Saúde Pública. Ao todo foram identificados, no Index Medicus, 28 textos se reportando ao binômio “adolescência e gravidez” no período compreendido entre 1950 e 1959. Destes, teve-se acesso efetivo a 19 textos, o que veio representar $70 \%$ da literatura disponível no período.

Muito embora a maior parte dos textos, disponíveis e efetivamente retidos para fins de análise, seja de origem americana tem-se, de maneira geral, que eles pertencem em sua quase totalidade à área biomédica (89\%). Assim, dos 19 textos, 15 se reportam à área de conhecimento Obstétrico Pediátrico, enquanto que 2 se remetem à área da Clínica Médica e 2 à Saúde Pública. 
Tabela 1 - Áreas de conhecimento da literatura sobre adolescentes grávidas segundo países no período de 1950-1959

\begin{tabular}{lcccc}
\hline \multicolumn{5}{c}{ Áreas do conhecimento } \\
Paises & Obstétrico-Pediátrico & Saúde Pública & Clínica Médica & Total \\
\hline Canadá & 1 & - & - & 1 \\
E.U.A. & 11 & 1 & 1 & 13 \\
Grã-Bretanha & 1 & 1 & - & 2 \\
Itália & 1 & - & - & 1 \\
Noruega & 1 & - & 2 & 19 \\
Total & 15 & 2 & & \\
\hline
\end{tabular}

Fonte Reis, 1993

Tabela 2 - Áreas de conhecimentos da literatura sobre adolescentes grávidas segundo países no período de 1960-1969

\begin{tabular}{|c|c|c|c|c|c|c|}
\hline \multicolumn{7}{|c|}{ Áreas do conhecimento } \\
\hline Paises & Obst.-Ped. & Saúde Públ. & Nutrição & Psicologia & Educação & Total \\
\hline Austrália & 1 & - & - & - & - & 1 \\
\hline Canadá & - & 1 & - & - & - & 1 \\
\hline E.U.A. & 5 & 5 & 1 & 7 & 5 & 23 \\
\hline Finlândia & 1 & - & - & - & - & 1 \\
\hline França & 1 & - & - & - & - & 1 \\
\hline Grã-Bretanha & 4 & 2 & - & - & - & 6 \\
\hline México & 1 & - & - & - & - & 1 \\
\hline Total & 13 & 8 & 1 & 7 & 5 & 34 \\
\hline
\end{tabular}

Fonte Reis, 1993

No que diz respeito ao período da década de 60, teve-se acesso a 34 textos da produção literária referente à adolescente grávida de um total de 66 disponíveis. Observa-se, de igual maneira, a predominância, no Index Medicus, de referências americanas. Contudo, neste período, a área Obsté-

Gráfico 1 - Áreas de conhecimentos da literatura sobre adolescentes grávidas. Período de 19501959
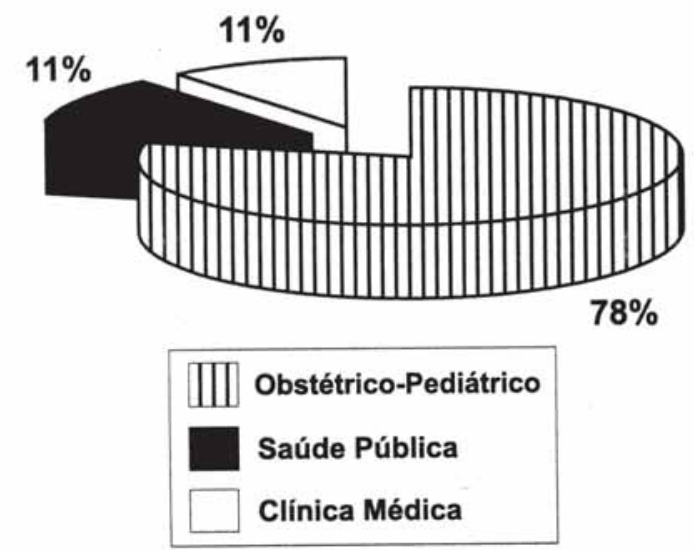

trico-Pediátrica passa a responder por apenas 13 textos de um total de 34, enquanto que a da Saúde Pública sustenta 8 textos. Quase com mesma importancia, a Psicologia aparece como uma área de conhecimento responsável pela produção de 7 textos, a Educação 5 e, finalmente, a Nutrição 1.

Gráfico 2 - Áreas de conhecimentos da literatura sobre adolescentes grávidas. Periodo de 19601969
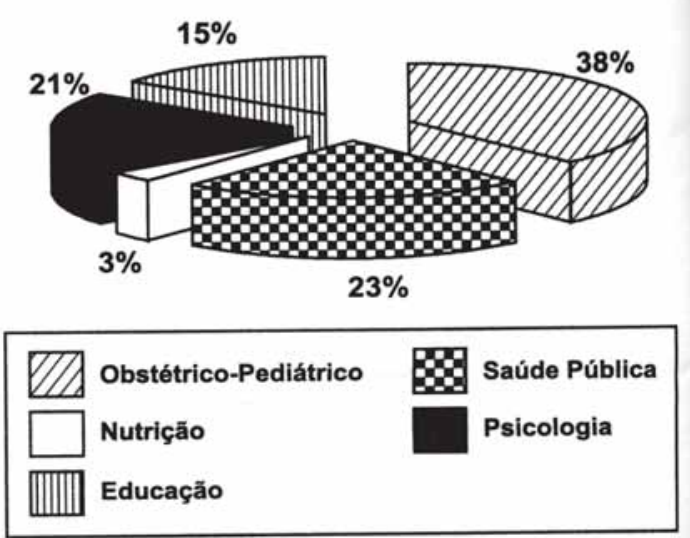
Quando se comparam as porcentagens destes valores relativos às décadas de 50 e 60 , tal como pode ser observado nos gráficos 1 e 2, percebe-se que existe uma nítida transformação do quadro epistemológico de sustentação dos textos referentes à adolescente grávida.

Assim, as publicações estribadas em uma referência Obstétrico-Pediátrica passam a representar 38\% das publicações, significando uma importante retração percentual em relação à década anterior. Os textos de Clínica Médica desaparecem, cedendo espaço para aqueles referentes à Saúde Pública, Nutrição e aos pertencentes às chamadas Ciências Humanas, a saber, Educação e Psicologia. Os de Saúde Pública passam a ocupar 23\% da literatura, mais do que dobrando em relação à década anterior (11\%), enquanto aqueles atinentes às Ciências Humanas representam $38 \%$ passando a igualar-se com os da área Obstétrico-Pediátrica.

O recuo e o apequenamento desta temática significou a desarticulação de um discurso, cujo raciocínio, votado à adolescência e à reprodução, permanecia apenso à figura da mulher na medida em que esta se estabelece como sede, locus e manifestação imediatamente visível do processo reprodutivo.

A mudança de enfoque temático, operada a partir dos anos 60, deveu-se ao impacto dos movimentos americanos de recomposição da prática médica sobre o discurso da Saúde Pública que, então, incidia sobre a adolescente grávida. A despeito desses movimentos terem, de acordo com ALVARENGA (1984), ganhado amplitude nas últimas décadas da primeira metade do século XX, seus efeitos só se fizeram sentir, no âmbito da reprodução adolescente, a partir dos anos 60 .

A proposta de recomposição da prática médica, que passou a articular a Medicina Integral com a Medicina Preventiva, deu-se "a partir do estabelecimento de dois procedimentos: a manipulação de aspectos parciais da estrutura da dimensão social da realidade à prática médica. Em função disto, houve a necessidade de descentra-mento do enfoque biológico" (DONNANGELO \& PEREIRA, 1976 p.80) e, segundo ALVAREN-GA (1984), a promoção de uma concepção globalizadora do objeto individual visando a apreensão da totalidade biopsicosocial.

Encontravam-se criadas, desta forma, as condições intelectuais e epistemológicas para que se passasse, então, a considerar uma multiplicidade de elementos que, inscritos na problemática das adolescentes, viriam resgatá-la da estreitura da dimensão biológica.
As mudanças ocorridas nos anos 60 estabeleceram as bases que determinariam o início de uma nova perspectiva no enfoque da questão da maternidade adolescente. A superação dos contornos no interior dos quais fora, até então, enunciada a questão da adolescente grávida permitiu o evidenciamento de uma nova tendência que, abarcando a totalidade do âmbito cultural dos adolescentes, passou a incluir os gêneros masculino e feminino, não se limitando mais a circunscrever-se, exclusivamente, à mulher.

Contudo, tal processo não se evidenciou imediatamente. Foi apenas a partir dos anos 80 que se passou a mencionar, ainda que discretamente, a figura do pai adolescente.

\section{A DÉCADA DE 80: O DESVELAMENTO}

A análise dos temas que compõem a temática discursiva do decênio de 80, tal como vem a ser depreendida dos textos de divulgação científica, mostra que a reprodução adolescente começou a ser tratada numa perspectiva nova: longe de ater-se à parcialidade do universo feminino, ela plasma-se no bojo da problemática geral da adolescência onde dos gêneros em definição encontram as razões complexas do existir.

Os temas, obtidas através da extração e categorização de núcleos de sentido, por intermédio da análise de conteúdo efetuada na população dos textos retidos, referentes à década de 80 , encontram-se dispostos, em ordem de freqüência decrescente, na tabela 3.

No interior da organização geral dos temas, a Educação aparece como categoria mais freqüen-temente tratada nos textos. Em seguida, observa-se que os temas Psicologia e Economia, este último remetendo-se às considerações de autonomia material da existência do jovem, ocupam 9\% do total de considerações pertinentes quando se tem por foco a adolescente grávida. Contudo, para os presentes propósitos, o que se destaca na tabela 3 é a presença significativa de referências ao pai adolescente nos anos 80. Estas ocupam $4 \%$ dos principais núcleos de sentido em torno dos quais se organizam os textos de Saúde Pública acerca da adolescente grávida, juntamente, e em igual fieqüência, a temas tradicionalmente importantes no que se refere ao objeto investigado tal como a "maternidade muito precoce", isto é, entre os 10 e 14 anos de idade, entre outros.

Na década anterior, como se pode observar pela comparação dos temas então prevalentes nos anos 70 e 80, referências à paternidade ado- 
Refere-se ao Art. de mesmo nome. 7(2). 6.9-76. 1997

Rev. Bras. Cresc. Des. Hum. S. Paulo, 7(2), 1997

Tabela 3 - Principais temas da literatura referente à adolescente grávida - décadas de 70 e 80

\begin{tabular}{|c|c|c|c|c|}
\hline \multirow{2}{*}{ Temas } & \multicolumn{2}{|c|}{ Década de 70} & \multicolumn{2}{|c|}{ Década de 80} \\
\hline & $\mathrm{N}$ & $\%$ & $\mathrm{~N}$ & $\%$ \\
\hline Educação & 51 & 19 & 38 & 13 \\
\hline Economia & 24 & 8 & 26 & 9 \\
\hline Psicologia & 33 & 12 & 25 & 9 \\
\hline Aborto & 17 & 6 & 22 & 8 \\
\hline Obstétrico-pediátrico & 25 & 9 & 22 & 8 \\
\hline Racial & 17 & 6 & 21 & 7 \\
\hline Solteirismo & 13 & 5 & 20 & 7 \\
\hline Ilegitimidade & 19 & 7 & - & - \\
\hline Gravidez não esperada & - & - & 5) & \\
\hline Não planejada & - & - & $9\}=9$ & 7 \\
\hline Não desejada & - & - & 5] & \\
\hline Pré-natal & 17 & 6 & - & - \\
\hline Variação demográfica & 30 & 11 & 15 & 5 \\
\hline Hiperprecocidade materna & 16 & 6 & 15 & 5 \\
\hline Recidividade & 15 & 5 & - & - \\
\hline Crescimento/desenvolvimento & - & - & 14 & 5 \\
\hline Paternidade adolescente & - & - & 12 & 4 \\
\hline Abrangência & 9 & 3 & 11 & 4 \\
\hline Social & 12 & 4 & 11 & 4 \\
\hline Jurídico-legal & 14 & 5 & 11 & 4 \\
\hline Família & - & - & 9 & 3 \\
\hline Total & 270 & 100 & 285 & 100 \\
\hline
\end{tabular}

lescente não eram sequer mencionadas de maneira significativa.

A análise dos temas mostra que o discurso dos anos 80, ao permitir o advento da figura do adolescente masculino, incluindo-a na equação da adolescente grávida, passou a revelar o que até então se velava, a saber, o significado da longa ausência do género masculino no âmbito de tais considerações. Ora, este apartamento não é sem efeito, nem tampouco uma mera negatividade. Ao contrário, esta ausência, longe de se apresentar como lacuna, pode ser estimada como sendo um fragmento positivo de um discurso sobre a adolescente uma vez que todo discurso implica silêncios plenos de significação. A psicanálise, em particular, tem mostrado, desde que Freud se pôs a escutar os sons dos silêncios de suas pacientes, o papel de pontuação e de determinação de sentido exercido por estes "brancos" que se introduzem no discurso e se revelam na escanção das falas do suj eito. Por outro lado, no contexto da problemática dos géneros, cabe salientar que o silêncio acerca do papel masculino no processo de gravidez da adolescência, consubstancializado na elisão da participação paterna, incidiu, antes de tudo, so- bre a mulher adolescente. Este emudecimento veio colocá-la solitária no núcleo de um debate que, na verdade, deveria envolver não só o pai adolescente como o conjunto da sociedade e da cultura.

No que tange ao adolescente masculino participando do processo da reprodução sexual, o silêncio que isolou a mulher adolescente vem marcá-lo duplamente. Em primeiro lugar, aliena-o na categoria da não-existência, precipitando-o num Nada. A este propósito, Sófocles, em Édipo Rei, mostra que Laios, em sua tentativa de escapar à maldição que lhe perseguia, vota a seu filho um desejo de morte. A corporificação deste desejo se fez, em primeira instância, pela não atribuição de um nome. Sófocles aponta para o fato de que aquilo que não é nomeado não existe na esfera humana que é, afinal, o reino da linguagem. De igual modo, a não nomeação do pai adolescente nos textos de Saúde tem como função aboli-lo como referencial real.

Em segundo lugar, este silêncio vem marcar o adolescente em seu reverso. Em torno do espaço vazio aberto pela escotomização de gênero masculino no cálculo da equação da gravidez da adolescente condensam-se e 
aglutinam-se mitos, um anedotário e estigmas históricos. Esta borda preconceituosa que delimita o vazio e a ausência de dados concernentes à paternidade adolescente foi, parcialmente, analisada por ROBINSON (1988). Este autor descreveu os principais estereótipos aplicados ao pai adolescente. Segundo ele, muito embora tais mitos visem estabelecer uma imagem, segundo a qual a irrespon-sabilidade é característica destes pais, tais idéias não encontram respaldo nos dados de pesquisa que começaram a ser levadas a cabo a partir dos finais de 80. Estas investigações indicam, contrariamente às representações correntes, que os pais adolescentes não tendem a abandonar suas parceiras quando estas engravidam ou se tornam mães. Estes jovens pais, uma vez inscritos em programas de saúde específicos, tornam-se particularmente competentes e provedores.

\section{CONCLUSÃO}

O movimento, iniciado na década de 80 , de superação dos limites no interior dos quais, até então, se enunciava a questão da adolescente grávida veio apontar para o fato de que esta problemática não se circunscreve à figura da mulher, mas se molda no âmbito cultural do comportamento dos adolescentes considerados em sua generalidade. $\mathrm{O}$ aparecimento de preocupações relativas à figura do pai adolescente evidencia-se a partir da década de 80 quando se pode detectar, em textos de Saúde Pública, a presença tímida mas já significativa de temas atinentes a este assunto. A importancia da assumpção destes temas reside, mais profundamente, no fato de que não é só a paternidade que passa a ser contemplada no discurso da Saúde Pública acerca da adolescente grávida. Mais. Trata-se da inclusão da figura do masculino, até então esmaecida, no cenário em que evoluiam as questões apensas à adolescente grávida. PITT (1986) observa, a este propósito, que "adolescent pregnancies are not exclusively female problems [...] it becomes clear that there will be no resolution of the problem of teenage pregnancy without directing greater attention to lhe male" (p. 45).

Indo além da perspectiva mais pragmática direcionada à resolução específica desta problemática adolescente sugerida por Pitt torna-se mister sublinhar que a visibilidade da paternidade pode não só trazer novas perspectivas de enfoque desta maternidade, como vir a distribuir mais eqüitativamente uma responsabilidade que, uma vez concentrada sobre a mulher, particularmente a adolescente, só podia penalizá-la.

Finalmente, resta indicar que os estudos e investigações contemporâneos da área da Saúde que contemplam, hoje, com largueza, profundidade e abundância a questão dos gêneros podem encontrar muito provavelmente nos avatares do discurso da Saúde Pública acerca da adolescente grávida parte importante de seus fundamerntos.

\begin{abstract}
Through lhe analysis of scientific promotion texts, lhe present article aims lo identify lhe epistemological conditions that made possible lhe emergence of the issue of adolescent paternity in lhe scope of Public Health concerns referring to pregnancy and maternity in lhe young age. Also, the present investigation intends to promote reflection in order to elucidate the role played by the hiding of the paternity theme in scientific texts whose object is the adolescent woman's reproduction process.
\end{abstract}

Key-words: adolescent paternity, pregnant adolescent, public health.

\section{REFERÊNCIAS BIBLIOGRÁFICAS}

ALVARENGA, A. T. O Conceito de Risco na Área Materno-Infantil: Considerações Teórico Metodológicas e de Aplicação. São Paulo, 1984. [Tese de Doutorado, Faculdade de Saúde Pública, Universidade de São Paulo].

BARDIN, L. Análise de Conteúdo, Lisboa, Edições 70, 1980, p. 9.

DONNANGELO, M. C. F. \& PERREIRA, L. Saúde e Sociedade. São Paulo, Duas Cidades, 1976, p. 80.

KUHN, T. S. A estrutura das revoluções cientificas, São Paulo, EditoraPerspectiva, 1978.
ORGANIZACIÓN PANAMERICANA DE LA SALUD, El Embarazo y el Aborto en la Adolescencia. Genebra, Organizacion Mundial de la Salud 1975 (OMS Séries de informes Técnicos, 583).

PITT, E, Targeting the Adolescent Male, Journal of CommunityHealth, 11(1): 45-8, 1986.

REIS, A. O. A. A saúde pública face à adolescente grávida. In: "Simpósio Franco-Brasileiro sobre prevenção da mortalidade materna com ênfase na gravidez na adolescência. Anais. São Paulo, Departamento de Saúde Materno-Infantil da Faculdade de Saúde Pública da USP. 1992. (Série Investigação em saúde da mulher, da criança e adolescência, 2). 
REIS, A. O. A O discurso da saúde pública sobre a adolescente grávida: Avatares. São Paulo, 1993. [Tese de Doutorado, Faculdade de Saúde Pública, Universidade de São Paulo].

REIS, A. O. A \& ZIONI, F. G. O Papel do feminino na construção do conceito de adolescência. Rev de Saúde Pública, 27(6): 472-77, 1994.
REIS, A. O. A Análise metafórico-metonímica do processo de constituição do pensamento da saúde pública acerca da adolescente grávida: os anos 60. Cad. de Saúde Pública, 14(1): 115123, 1998.

ROBISON, B. E. Teenage pregnancy from the father's perspective. American Journal of Orthopsychiatry, 58(1): 46-51, 1988.

SOARES, M. B. Alfabetização no Brasil: o estado do conhecimento. Brasília. Reduc II, 1988. 